\title{
Different method for diagnosis bacterial vaginosis in married woman in Hilla city
}

\author{
Sura I. A. Jabuk ${ }^{1}$, Raflaa S.H. Hussian ${ }^{2}$, Susan I. A. Jabuk ${ }^{3}$ \\ ${ }^{1,2}$ University of Babylon, College of science, Department of Biology ,Hilla, Iraq \\ ${ }^{3}$ Al hilla teaching hosbital Babylon health directorate
}

\begin{abstract}
Bacterial vaginosis $(B V)$ is an ecological disorder of the vaginal microbiota that affects millions of women annually, and is associated with numerous adverse health outcomes including pre-term birth and the acquisition of sexually transmitted infections. This study aimed to compare between the different methods (Amsel's, Nugent's, Spiegel's and PAP smears) of BV diagnosis. The results revealed that from the 100 patients It was observed that 48 (48\%) were BV positive, they met three or four of Amsel's criteria . 56(56\%) were diagnosed with $B V$ and $45(45 \%)$ had normal vaginal flora based on Nugents' score. comparison between Nugent's score and Amsel's criteria for diagnosis of BV showed a sensitivity $81 \%$ and specificity $75 \%$. when diagnosis bacterial vaginosis by Spiegel's criteria observed that 24 (24\%) of the 100 cases, were BV positive while $76(76 \%)$ cases were BV negative while $57(57 \%)$ cases were BV negative by using pap smear including presence of Bacterail vaginosis with Trichomonas \& candida $16(16 \%)$, Bacterail vaginosis with Trichomonas $20(20 \%)$ and Bacterail vaginosis only $7(7 \%)$ in BV positive cases. The comparison between Nugent's score and Pap smears for diagnosis of $B V$ had a sensitivity of $62 \%$ and a specificity of $81 \%$.
\end{abstract}

Key words: Bacterial vaginosis, Amsel's criteria, Nugent's score, Spiegel's criteria and Papanicolaou smears.

\section{Introduction:}

The adult human vagina is a complex ecosystem containing an abundance of microorganism. The vagina and its unique micro flora form a finely balanced ecosystem, with the vaginal environment controlling the presence of microbes and the microflora, in turn, controlling the vaginal environment (1).

Vaginal microbial communities play a role in colonization resistance, protection against invasion by pathogens and dominance by potentially pathogenic species among the normal flora. Thus, perturbations of the vaginal community structure may predispose individuals to various infectious diseases (2).

Bacterial vaginosis is a polymicrobial syndrome in which a decrease in vaginal acidity and concentration of lactobacilli is accompanied by an increase of other pathogenic micro-organisms such as Gardnerella vaginalis and Mobiluncus spp. (3).

Bacterial vaginosis (BV) and Trichomonas vaginalis (TV) infection have been estimated to affect as many as one-quarter to one-third of sexually active females worldwide (4), and are often found concurrently (5) . Both BV and TV have been associated with adverse birth outcomes such as prematurity and low birth weight ( 6 ), pelvic inflammatory disease(7) infertility(8), and acquisition of HIV and Herpes Simplex Virus type 2 (HSV-2) infections(9). Surprisingly, given the well-described association between BV and TV, few data that would help clarify the temporality of the relationship between BV and TV infection are available. Understanding the relationship between BV and TV has been problematic because most studies have been crosssectional (10) . Nevertheless, results of a number of studies suggest that TV colonization is increased in the presence of BV-defining phenomena such as elevated amine production, loss of facultative lactobacilli, and increased $\mathrm{pH}$ (11). The aim of this study to compare between the different methods of BV diagnosis.

\section{Material \& method}

1-Patients:

The study was carried out on one hundred patients attending Babylon hospital for maternity and pediatrics and education hilla hospital in Babylon province, Iraq during the period from November 2013 to April 2014. The patients included in this study were in the age range from (20-45) years. All patients were examined using speculum without lubrication and the presence of vaginal erythema and vaginal discharge was recorded with description of the color, consistency and odor of discharge. Then vaginal swabs were taken and transported immediately to the microbiology laboratory at biology department,Babylon University.

\section{2-Amsel's criteria}

Clinical diagnosis using Amsel's criteria requires that at least three of the following four criteria are met: first, a vaginal $\mathrm{pH}$ of greater than $\mathrm{pH} 4.5$; second, the presence of clue cells in the vaginal fluid when examined in a wet mount; third, a milky homogeneous vaginal discharge (There must not be any granular 
elements; the fluid must be completely homogenous); and finally, positive Whiff (Sniff) test. Vaginal pH was measured by rolling the swab over a pH strip immediately after swabbing and the resulted color is translated into the $\mathrm{pH}$ value (12). Clue cells are epithelial cell it was detected by microscopic examination of wet mount which was made by mixing the vaginal discharge from the swab with a drop of saline (13). homogenous milky discharge was detected by examination after speculation. Whiff test was done by mixing the vaginal discharge from a swab with a drop of $10 \% \mathrm{KOH}$; a positive result is a "fishy" amine odor (14).

\section{3-Gram stain and Nugent scoring system:}

After rolling the vaginal swab on a microscopic slide, it was left to dry then gram stained with gram staining protocol, then it was read by a single experienced microbiologist to eliminate the possibility of interobserver difference. Slides were read according to Nugent score as follows: Morphotypes were counted as the average number of bacteria in 10-20 oil immersion field. The Nugent score was calculated by assessing for the presence of large gram-positive rods (Lactobacillus morphotypes; decrease in Lactobacillus scored as 0 to 4), small gram-variable and gram-negative rods (G. vaginalis and Bacteroides morphotypes; scored as 0 to 4), and curved gram-variable rods (Mobiluncus spp. morphotypes; scored as 0 to 2), After the amount of each morphotype detected on the smear was graded it was then allocated a score as shown in Table (1). Then total score calculated from 0 to 10 . A score of 1-3, considered normal, a score of 4-6 considered intermediate (means an intermediate state between normal and BV) and a score of 7 to 10 was consistent with BV. This method is considered the gold standard for diagnosis of BV (15).

Table 1. Gram-staining Scoring System

\begin{tabular}{|l|l|l|l|}
\hline Score & $\begin{array}{l}\text { (A) } \\
\text { Lactobacillus } \\
\text { Morphotypes }\end{array}$ & $\begin{array}{l}\text { (B) } \\
\text { Gardnerella and Bacteroides spp. } \\
\text { Morphotypes }\end{array}$ & $\begin{array}{l}\text { (C) } \\
\text { Curved-gram variable rods } \\
\text { Morphotype }\end{array}$ \\
\hline 0 & $4+$ & $\mathbf{0}$ & $\mathbf{0}$ \\
\hline 1 & $3+$ & $1+$ & $1+o r 2+$ \\
\hline 2 & $2+$ & $2+$ & $3+o r 4+$ \\
\hline 3 & $1+$ & $3+$ & $4+$ \\
\hline 4 & 0 & $4+$ & $4+$ \\
\hline
\end{tabular}

Morphotype scoring is based on the number per field of view. 0 , no morphotypes present; $1+,<1$ morphotype present; 2+, 1 to 4 morphotypes present; 3+, 5 to 30 morphotypes present; 4+, >30 morphotypes presen

\section{4- Diagnosis by Spiegel's criteria}

When the gram staining showed predominance (3 to $4+)$ of the lactobacillus morphotype with or without the Gardnerella morphotype, it was interpreted as normal. When the gram staining showed a mixed flora consisting of gram-positive, gram negative, or gram-variable bacteria and the lactobacillus morphotype was decreased or absent ( 0 to $2+$ ), the gram staining was interpreted as consistent with bacterial vaginosis (16).

\section{5- Papanicolaou ( Pap) smear:}

Diagnosis of BV with Pap smear used the Bethesda criterion. To be considered positive for BV the smear must satisfy all three criteria: first presence of coccobacilli flora , second present of clue cells, and absence of lactobacilli flora .Coccobacilli seen in Pap smears were assumed to be composed mainly of G. vaginalis, but no morphocyte count was done. Unlike wet preparation, the Bethesda criterion does not require estimation of clue cell percentage. Pap smears having one or two of the criteria were reported as intermediate or altered flora, which together with diagnosis of lactobacilli flora and no microbes present were considered negative for BV. Candida sp was diagnosed when pseudo-hyphae were seen, weakly stained with eosin or sometimes with hematoxylin, and/or small spores (diameters of 2-4 mm), stained pale pink. Trichomonas vaginalis was diagnosed when a unicellular organism of ovoid or rounded shape was viewed (diameter of 8- 20 $\mathrm{mm}$ ), with pallid or grayish cytoplasm. It could have eosinophilic granules at its center and a vesicular or crescent-shaped nucleus, lightly stained by hematoxylin (17).

Results of simplified Amsel's criteria and Pap smear tests were compared with the reference standard (Nugent criteria). The sensitivity, specificity were evaluated for a positive test.

\section{6- Statistical analysis:}

Statistical analysis was conducted using SPSS software. Kappa values and degrees of agreement of the diagnostic methods were determined. 


\section{1- Amsel's criteria:}

\section{Result:}

It was observed that 48 (46\%) of the 100 cases, were BV positive, they met three or four of Amsel criteria while 52 (52\%) cases were BV negative Table (3). Table (3) shows the results of Amsel criteria including presence of milky homogenous discharge 40 (83.4\%), increase of $\mathrm{pH}(>4.5) 43(89.6 \%)$, positive whiff test $38(79.1 \%)$ and presence of clue cells $45(93.8 \%)$ in BV positive cases.

Table (2): Distribution of bacterial vaginosis according to Amsel's criteria

\begin{tabular}{|l|l|l|l|}
\hline Age & $\begin{array}{l}\text { Infection } \\
\text { No(\%) }\end{array}$ & Non infection No(\%) & $\begin{array}{l}\text { Total } \\
\text { No(\%) }\end{array}$ \\
\hline$<20$ & $4(4)$ & $11(11)$ & $15(15)$ \\
\hline $21-30$ & $20(20)$ & $17(17)$ & $37(37)$ \\
\hline $31-40$ & $14(14)$ & $15(15)$ & $29(29)$ \\
\hline$>40$ & $10(10)$ & $9(9)$ & $19(19)$ \\
\hline Total No(\%) & $48(48)$ & $52(52)$ & $100(100)$ \\
\hline
\end{tabular}

p>0.05 no significant difference

Table (3): Incidence of Amsel's criteria in BV positive cases $n=48$

\begin{tabular}{|l|l|l|}
\hline Individual criterion & Positive cases No. $(\%)$ & Negative cases No. $(\%)$ \\
\hline 1- Homogenous discharge & $40(83.4)$ & $8(16.7)$ \\
\hline 2- $\mathrm{pH}>4.5$ & $43(89.6)$ & $5(10.4)$ \\
\hline 3- Whiff test & $38(79.1)$ & $10(20.8)$ \\
\hline 4- Presence of clue cells & $45(93.8)$ & $3(6.2)$ \\
\hline
\end{tabular}

p $>0.05$ no significant difference

\section{2-Nugent score:}

Of the 100 women, 56(56\%) were diagnosed with BV and 45(45\%) had normal vaginal flora based on Nugents' score. The microbiological evaluation of vaginal microflora pattern was made using Nugent scoring system that was based on counting the bacterial cell types on the Gram stained slides of vaginal smears (Table 1). According to this study large Gram-positive bacilli were dominantly present in 45(45\%)of the women. The typical appearance of the organisms identified as having the Lactobacillus morphotype was evident for the absence of bacterial vaginosis and generally interpreted as normal flora (score 0-3). In 23(23\%) of the women, two or three bacterial morphotypes were evident. Stains showing the presenceof few Lactobacillus and many Gram-negative morphotypes (Gardnerella and/or Mobiluncus morphotype) were interpreted as intermediate flora (score 4-6). 33(33\%) of the women in relation to Table 1 showed complete absence or low presence of Lactobacillus morphotype and a smear consistent with BV (score 7-10).

Table (4): Distribution of bacterial vaginalis according to Nugent Score $\mathbf{n = 1 0 0}$

p>0.05 no significant difference

\begin{tabular}{|l|l|}
\hline Vaginal Flora (Nugent Score) & Positive case No(\%) \\
\hline Normal (0-3) & $\mathbf{4 5}(\mathbf{4 5})$ \\
\hline Intermediate (4-6) & $\mathbf{2 3}(\mathbf{2 3})$ \\
\hline Abnormal (7-10) & $\mathbf{3 2 ( 3 2 )}$ \\
\hline
\end{tabular}

Table 4 shows the comparison between Nugent's score and Amsel's criteria for diagnosis of BV. Nugent's score showed a sensitivity of 81 specificity of $75 \%$.

Table (5): Comparison between Nugent's score and Amsel's criteria for diagnosis of BV

\begin{tabular}{|l|l|l|l|}
\hline & Amsel's Positive & Amsel's Negative & Total \\
\hline Nugent's Positive & 44 & 12 & 56 \\
\hline Nugent's Negative & 4 & 40 & 32 \\
\hline Total & 48 & 52 & 100 \\
\hline
\end{tabular}

p>0.05 no significant difference

Sensitivity:91\%

Specifity:76\%

3- Spiegel's criteria :It was observed that 24 (24\%) of the 100 cases, were BV positive while $76(76 \%)$ cases were normal Table (6).

Table (6): Distribution of bacterial vaginalis according to Spiegel's criteria $n=100$

\begin{tabular}{|l|l|}
\hline Spiegel's criteria & Positive case No(\%) \\
\hline Normal & 76 \\
\hline Bacterial vaginosis & 24 \\
\hline
\end{tabular}


4- Pap smear : It was observed that 43 (43\%) of the 100 cases, were BV positive, while 57 (57 \%) cases were BV negative. Table (6) shows the results of pap smear including presence of Bacterail vaginosis with Trichomonas \& candida $16(16 \%)$, Bacterail vaginosis with Trichomonas 20(20\%) and Bacterail vaginosis only $7(7 \%)$ in $\mathrm{BV}$ positive cases.

Table( 7). Presence of BV in Pap Smears with and without Trichomonas\& candida $\mathbf{n = 1 0 0}$

\begin{tabular}{|l|l|}
\hline Pap smear & Case No(\%) \\
\hline Bacterail vaginosis with Trichomonas\& candida & 16 \\
\hline Bacterail vaginosis with Trichomonas & 20 \\
\hline Bacterail vaginosis only & 7 \\
\hline Normal & 57 \\
\hline
\end{tabular}

p>0.05 no significant difference

The comparison between Nugent's score and pap smear had a sensitivity of $62 \%$ and a specificity of $81 \%$ (Table 7).

Table( 8). Comparison between Nugent's score and Pap smear for diagnosis of BV

\begin{tabular}{|l|l|l|l|}
\hline & Pap smear positive & Pap smear negative & Total \\
\hline Nugent's positive & 35 & 8 & 43 \\
\hline Nugent's negative & 21 & 36 & 57 \\
\hline Total & 56 & 44 & 100 \\
\hline
\end{tabular}

p>0.05 no significant difference

Sensitivity:62\%

Specifity:81\%

\section{Discussion:}

Vaginitis is a common medical problem in women that can be associated with significant morbidity and complications. Bacterial vaginosis being one of the important causes of vaginal discharge during pregnancy merits early and accurate diagnosis as it can lead to serious complications like premature rupture of membranes, chorioamnionitis, preterm delivery postpartum and endometritis. The diagnosis of bacterial vaginosis is based on clinical findings and laboratory testing. Clinically Amsel criteria are the most widely accepted for the diagnosis of bacterial vaginosis. Regarding Amsel criteria, our study found that 48 (48\%) of the 100 cases, were BV positive as they met three or four of Amsel criteria. There was no significant difference between infection and non infection bacterial vaginosis and between Amsel criteria. Lower rates of BV incidence were obtained by studies $(18,19,20)$. in which BV was diagnosed $24 \%, 18 \% \& 24 \%$ of cases by Amsel's criteria. And higher rates of BV incidence were reported by other studies $(21,22)$ which reported $62 \% \& 58 \% \mathrm{BV}$ incidence rate. In comparison with Nugent's criteria as a gold standard, we found that Amsel's criteria had 91\% sensitivity, 76\% specificity. (23) reported lower sensitivity (66.67\%), and similar specificity $(94.74 \%)$. (21) reported a lower sensitivity of (77\%) and higher specificity (91\%). (24), obtained a lower sensitivity (69\%) similar specificity $(93.1 \%)$.

Alternatively bacterial vaginosis (BV) can be diagnosed by gram stain which is probably the most reliable method to differentiate BV from other vaginal infections. The same authors (25) also developed a grading system for gram stain of vaginal discharge based on presence or absence of certain bacterial morphocytes (and their relative numbers), which gives more objective assessment of BV (25). Regarding Nugent score as a method of BV diagnosis, $56 \%$ of cases were diagnosed to be BV positive . There was no significant difference between different criteria of nugent's score . Lower percentages of BV prevalence using Nugent's method were reported by some studies $(26,27,23,18,19)$, Which reported BV incidence rates of $7.1 \%, 19 \%, 24 \%, 23.03 \%$ and $19 \%$ respectively. Similar percentages were obtained by other studies $(28,29,22)$ , which reported BV prevalence rate as $32 \%, 36.7 \%$ \& $31.6 \%$ respectively. Higher percentage were obtained by (21), who found that BV incidence rate was $78 \%$. These differences in the incidence rates may be due to difference in the geographical distribution, hygienic measures and sexual habits between our research area and those studies' research areas.

Vaginal culture has got no role in the diagnosis of bacterial vaginosis therefore it is advised that Amsel's criteria may be used for he diagnosis. Gram staining although a reliable diagnostic method but is mostly performed in research studies because it is more cumbersome to use it in clinical practice than Amsel's criteria (30,31). Therefore whenever clinical criteria is used the sensitivity reported from gram staining has ranged from $62-100 \%$. However a definitive advantage of gram staining is that it is more objective as slide can be stored for future reference. The main difficulty forclinician is the lack of access to direct microscopy. A pH paper is also cheap and normal vaginal $\mathrm{pH}$ virtually exclude BV. The whiff test is also easy to do with high specificity and sensitivity. Therefore the diagnosis of bacterial vaginosis according to Amsel's criteria may be simplified in settings where gram staining is not available (32). 
So, it is evident that women with intermediate flora must be considered separately. Hence, Spiegel's criteria which divides women into only 2 categories, namely, bacterial vaginosis and normal flora, is not as popular as Nugent's method. There are many studies which have tried to formulate better gram stain scoring systems, but these are not as popular as Nugent's method of the diagnosis of bacterial vaginosis Statistical analysis present there was no significant difference between Nugent's criteria and Spiegel's criteria $(33,34)$.

It classifies gram stained vaginal smears into normal, intermediate and bacterial vaginosis based on the gram stain scoring system. The standardized score had an improved intercenter reliability as compared to Spiegel's criteria which divided the gram stained vaginal smears into only 2 categories, namely, normal or bacterial vaginosis $(15,35)$.

Archived Pap-stained vaginal smears can be used to follow the frequency of BV longitudinally in a population that has been screened for cervical cancer over time. This makes it possible to study whether BV has been a constant condition for many years. However, published reports do not provide a consensus about the efficacy of PAP-stained smears in BV diagnostics. Therefore, this study aimed to validate the use of PAPstained smears for the diagnosis of BV. Pap-staining of vaginal smears is shown to be a useful instrument for diagnosing BV compared with the Amsel clinical criteria as well as with the mean Nugent score, in both Gram stained smears and rehydrated air dried smears. With regard to diagnostic accuracy, very little difference is found among the three staining methods when the same scoring system is used to compare the different staining methods. In many countries, Pap smears for cytopathological diagnosis in the screening of cervical dysplasia are taken only from the ecto- and endo-cervix (36).

However, provided that the samples are taken from equivalent locations (the vaginal fornix) and analyzed according to the same scoring criteria, no discernable difference in the diagnostic accuracy of the different smear-staining methods can be found. The PAP-stained vaginal smears can thus be used as a wholly adequate alternative to Gram-stained smears for BV diagnosis. It has been suggested that the presence of clue cells on the Pap smear agrees reasonably well with clinical criteria So Pap smear test which is a simple, quick, painless procedure employed to screen cervical cancer can also be used for diagnosing cervicovaginal infections. (37).

Similarly, although the Pap smear is not performed for detection of Trichomonas, it has been suggested that recognition of Trichomonas by Pap smear is specific, although insensitive (38). Statistical analysis present there was no significant difference between Nugent's criteria and pap smear. Although BV and Trichomonas have significant overlap in clinical and laboratory findings (bacterial cultures), few studies have explored the association. (39) found concomitant TV and BV in 15\% of pregnant women examined by wet smear, concluding that these were frequent coinfections. (40) evaluated the association of TV and BV on Pap smears. In their study, $44.4 \%$ of cases with TV also had BV, whereas only 5.5\% of TV-negative cases had BV. It has been postulated that and that this is the mechanism of facilitation of the development of BV in the presence of TV (40 ). (41) have also suggested that TV alters vaginal flora, predisposing to BV. Of note, in the study of (40) the prevalence of BV in the TV-negative controls was only $5.5 \%$, as opposed to the $24.5 \%$ in our controls, yet we are still seeing a significant difference. Our study lends additional support to the increased frequency of BV in the presence of TV. This study suggests that the diagnosis of BV should be considered when a diagnosis of TV is made on a Pap smear.

\section{References:}

[1]. Zhou, X.; Bent, S.; Schneider, M.; Davis, C.; Islam, M.\& Forney, L. (2003).Characterization of vaginal microbial communities in adult healthy women using cultivation-independent methods. Microbiol. 150: 2465-2573.

[2]. Vitali, B.; Pugliese, C.; Biagi, E.;Candela, M.; Turroni, S.; Bellen, G.; Donders G Brigidi P. Dynamics of Vaginal Bacterial Communities in Women Developing Bacterial Vaginosis, Candidiasis, or No Infection, Analyzed by PCR-Denaturing Gradient Gel Electrophoresis and Real-Time PCR. Appl Environ Microbiol 2007; 73: 57315741.

[3]. Bradshaw, S.; Morton, A.; Garland, M.; Morris, B.; Moss, L.\& Fairley, K. (2005). Higher-Risk behavioral practices associated with bacterial vaginosis compared with vaginal candidiasis. Obstet Gynecol. 106:105-114.

[4]. Atashili, J.; Poole, C.; Ndumbe, P.; Adimora, A.\& Smith, J. (2008). Bacterial vaginosis and HIV acquisition: a meta-analysis of published studies. AIDS (London, England). 22(12):1493.

[5]. Mitchell, H. (2004) Vaginal discharge-causes, diagnosis, and treatment. BMJ. 328(7451):1306.

[6]. Schwebke, J.R.\& Burgess, D. (2004) Trichomoniasis. Clin. Microbiol. Rev. 17(4):794 803.

[7]. Cherpes, T.L; iesenfeld, H.C.; Melan, M.A.; Kant, J.A.; Cosentino, L.A.; Meyn, L.A. (2006). The Associations Between Pelvic Inflammatory Disease, Trichomonas vaginalis Infection, and Positive Herpes Simplex Virus Type 2 Serology. Sex. Trans.dis. 33(12):747-752.

[8]. Pellati, D.; Mylonakis, I.; Bertoloni, G.; Fiore, C.; Andrisani, A.; Ambrosini, G. (2008). Genital tract infections and infertility. Euro. J. of obst. Gynecol. \& reprod. Boil. 140(1):3-11.

[9]. Madhivanan, P.; Bartman, M.T.; Pasutti, L.; Krupp, K.; Arun, A.; Reingold AL, et al. (2009). Prevalence of Trichomonas vaginalis infection among young reproductive age women in India: implications for treatment and prevention. Sex. Heal. 6(4):339-344.

[10]. Gatski, M.; Martin, D.H.; Clark, R.A.; Harville, E.; Schmidt, N.\& Kissinger, P. (2011). Co-Occurrence of Trichomonas vaginalis and Bacterial Vaginosis Among HIV-Positive Women. Sex. Trans. Dis. 38 (3) : 163-166.

[11]. Brotman, R. ; Klebanoff, M.; Nansel, T.; Yu, K.; Andrews, W.\& Zhang, J. (2010). Bacterial Vaginosis Assessed by Gram Stain and Diminished Colonization Resistance to Incident Gonococcal, Chlamydial, and Trichomonal Genital Infection. Journal of Infectious Diseases. 202(12): 1907. 
[12]. Ferris, D.G.; Francis, S.L.; Dickman, E.D.; Miler-Miles, K.; Waller, J.L.\& McClendon, N. (2006).Variability of vaginal pH determination by patients and clinicians. J. Am .Board. Fam. Med. 19:368-373.

[13]. Silonie, S. (2006). Clue cell. Indian J. Dermatol.Venerol.Leprol. 72: 3923.

[14]. Cohrssen, A.; Anderson, M.; Merrill, A.\& McKee, D. (2005). Reliability of the whiff test in clinical practice. J. Am. Board. Fam.Pract. 18:561-562.

[15]. Mohanty, S.; Sood, S.; Kapil, A.\& Mittal, S. (2010). Interobserver variation in the interpretation of Nugent scoring method for diagnosis of bacterial vaginosis. Indian. J. Med. Res.131:88-91.

[16]. Honest, H.; Bachmann, L.M.; Knox, E.M.; Gupta, J.K.; Kleijnen, J.\&Khan, K.S. (2004). The accuracy of various tests for bacterial vaginosis in predicting preterm birth: a systematic review. BJOG. 111(5):409-22.

[17]. Levi, A.W.; Harigopal, M.; Hui, P.;Schofield, K.\& Chhieng, D.C. (2011). Comparison of affirm VPIII and Pa-panicolaou Tests in the detection of Infectious Vaginitis. Am. J. Clin. Pathol.135:442-47.

[18]. Pavani, K. \& Saileela, K. (2013). Diagnosis of bacterial vaginosis in reproductive age group in tertiary health care hospital in south India: Comparison of clinical and microbiological criteria. J. Evolut. Med. Dent. Sci. 2(35): 6611-6615.

[19]. Udayalaxmi,B. ; Bhat,G. ; Kotigadde, S. \& Shenoy, S. (2011). Comparison of the Methods of Diagnosis of Bacterial Vaginosis. J. Clin. Diag. Res. 5(3): 498-501.

[20]. Begum,N. ; Muazzam,N. ; Shamsuzzaman, S.M.; Chowdhury,A. ; Rashid, A. \& Islam, D. (2010)Diagnosis of Bacterial Vaginosis by Acridine Orange Staining and its Comparison to Conventional Methods and Association of vaginalis with Bacterial Vaginosis. Bangla. J. Med. Microbiol. 4 (01): $37-42$.

[21]. Taj, Y. ; Nasir, D.; Kahkashan, N. \& Anjum, A. (2012). Sensitivity and specificity of rapid clinical diagnostic test for bacterial vaginosis and its analytical value. J. Dow. Uni. Health Sci. 6(3): 91-94.

[22]. Rangari, A.A. ; Parmjit, S. and Sharma , V.K. (2013). Comparison of the Amsel's composite clinical criteria and Nugent's criteria for diagnosis of bacterial vaginosis : A step towards preventing misdiagnosis, JARBS. Biol . Sciences. 5(1), 37-44.

[23]. Modak,T. ; Arora,P.; Agnes, C. ; Ray, R. ; Goswami,S. ; Ghosh, P. P. \& Das, N. K. (2011).Diagnosis of bacterial vaginosis in cases of abnormal vaginal discharge: comparison of clinical and microbiological criteria, J Infect Dev Ctries., 5(5): 353-360.

[24]. Khatoon, R. ; Jahan, N. ; Ahmed, S. \& Rabbani, T. (2013). Comparison of OSOM BV Blue test with conventional methods for diagnosis of bacterial vaginosis. Afr. J. Microbiol. Res. 7(28): 3698-3703.

[25]. Nugent, R.P.; Krohn, M.A.\& Hillier, S.L. (1991). Reliability of diagnosing bacterial vaginosis is improved by a standardized method of Gram stain interpretation. J. Clin. Microbiol. 29:297.

[26]. Alice, T.N.D. ; Kives, S. ; Merovtiz, L. ; Nitsch, R. ; Teessler, K. and Yudin, M.H. (2012) . Screening for Bacterial Vagin osis at the Time of Intrauterine Contraceptive Device Insertion: Is There a Role?. J. Obstet. Gynaecol. Can. 34(2) : $179-185$.

[27]. Mathew,R. ; Sudhakshina, R.; Kalyani, M. ; Jayakumar, S. ; Lal, B. \& Banu, S. (2011). Microbiological profile of vaginosis among women of the reproductive age group, who attended a tertiary care hospital. J. Clin. Diag. Res. 5(8): 1548-1551.

[28]. Ayenalem, S. ; Yusuf, L. \& Ashenafi, M. (2010). Lactic Acid Bacterial vaginosis among Outpatients in Addis Ababa. Ethiop. J. Health Dev. 24(3) 198-204.

[29]. Chaudhary, V.; Prakesh, V. ; Agarwal,K. ; Agrawal,V.K.; Singh, A. \& Pandey, S. (2012). Clinico-Microbiological profile of women with vaginal discharge in a tertiary care hospital of northern India, Intern. J. Med. Science. and Public. Health. 1(2): 75-80.

[30]. Allsworth, J. E.; Lewis, V. A.\& Peipert, J. F.(2008). Viral sexually transmitted infections and bacterial vaginosis: $2001-2004$ National Health and Nutrition Examination Survey data. Sex. Transm. Dis. 35:791-796.

[31]. Landers, D.V.; Wiesenfeld, H.C.\& Heine, R.P. (2004). Predictive value of the clinical diagnosis of lower genital tract infection in women. Am. J. Obstet. Gynecol. 190:1004.

[32]. Shahzadi, N.\& Irum, S. (2010).Rapid Clinical Diagnostic Tests for Bacterial Vaginosis and its Predictive Value International Journal of Pathology 8(2): 50-52.

[33]. Ison, C.A.\& Hay, P.E. (2002).Validation of a simplified grading of Gram stained vaginal smears for use in genitourinary medicine clinics. Sex. Transm. Infect.78:413-15.

[34]. Verhelst, R.; Verstraelen, H.; Claeys, G.; Verschraegen, G.\& Van Simaey, L . (2005).The characterization of vaginal microflora: Definition of a distinct grade that resembles grade I microflora and revised categorization of grade I microflora. BMC Microbiol. $5: 61-72$.

[35]. Demba, E.; Morison, L.; Maartem Schim, V.D.L., et al. (2005). Bacterial vaginosis, vaginal flora patterns and vaginal hygiene practices in patients presenting with vaginal discharge syndrome in the Gambia, West Africa. BMC. Infect. Dis.5:12-24.

[36]. Lamont, R. F.; Hudson, E. A.;Hay, P. E.; Morgan, D. J.; Modi, V.; Ison, C. A.; Taylor-Robinson, D. (1999). A comparison of the use of Papanicolaou-stained cervical cytological smears with Gram-stained vaginal smears for the diagnosis of bacterial vaginosis in early pregnancy. Int. J. STD AIDS 10:93-97.

[37]. Narasimha, A.; Nirup, N. C.; Chandhana, B.; Nishanth, N.\& Harendra, K.M. L. (2014). Spectrum of infections in cervico-vaginal pap smears. J. Clin. Biomed. Sci. 4(1):222-25.

[38]. Lobo, T.T.; Carvalho, S.E.; Costa, P.L.; Chagas, C.; Xavier, J.\& Simoes-Barbosa, A. A. (2003).Comparative evaluation of the Papanicolaou test for the diagnosis of trichomoniasis. Sex. Transm. Dis. 30:694-699.

[39]. Franklin, T.L.\& Monif, G.R. (2000). Trichomonas vaginalis and bacterial vaginosis. Coexistence in vaginal wet mount preparations from pregnant women. J. Reprod. Med. 45:131-134.

[40]. Demirezen, S.; Kormaz, E. \& Beksa, M.(2005). Association between trichomoniasis and bacterial vaginosis: examination of 600 cervicovaginal smears. Cent. Eur. J. Public Health. 13:96Y8.

[41]. Moodley, P.; Connolly, C.\& Sturm, A.W. (2002).Interrelationships among human immunodeficiency virus type I infection, bacterial vaginosis, trichomoniasis, and the presence of yeasts. J. Infect. Dis.185:69-73. 